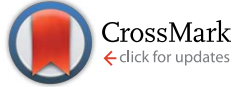

Cite this: RSC Adv., 2017, 7, 3204

Received 14th October 2016

Accepted 27th November 2016

DOI: $10.1039 / c 6 r a 25255 a$

www.rsc.org/advances

\section{Kinetics study of heterogeneous reactions of ozone with unsaturated fatty acid single droplets using micro-FTIR spectroscopy $\dagger$}

\begin{abstract}
Xiang He, Chunbo Leng, Shufeng Pang* and Yunhong Zhang*
Ozone initiated heterogeneous oxidation of micron-sized oleic acid (OA), linoleic acid (LA), and linolenic acid (LOA) single droplets was investigated using a gas-flow system combined with microscopic Fourier transform infrared (micro-FTIR) spectrometer. The pseudo-first-order rate constant $\left(k_{\text {app }}\right)$ and the overall uptake coefficient $(\gamma)$ are obtained by quantitatively estimating the changes in absorbance area of the $\mathrm{C}=\mathrm{O}$ stretching band at $1710 \mathrm{~cm}^{-1}$, which is assigned to the carboxyl group of the reactant. The overall kinetics is dominated by surface reaction. And the effect of surface adsorption, which is derived from the ozone concentration and particle size effects on reaction kinetics, plays an important role during the reaction. Comparison of the $k_{\text {app }}$ values corresponding to OA, LA and LOA shows the positive correlation between double bonds and reaction rate. In the view of $\mathrm{RH}$ effect, both $k_{\text {app }}$ and $\gamma$ are strongly enhanced by over a factor of three for the $\mathrm{LOA} / \mathrm{O}_{3}$ reaction system as the relative humidity $(\mathrm{RH})$ increases from $\sim 0 \%$ to $83 \%$. The $\mathrm{LA} / \mathrm{O}_{3}$ reaction system exhibits a weaker $\mathrm{RH}$ dependence. In contrast, the $k_{\text {app }}$ and $\gamma$ of the $\mathrm{OA} / \mathrm{O}_{3}$ reaction system are independent of the $\mathrm{RH}$ changes. Moreover, the various hygroscopicities of the three acids and corresponding products lead to different reactivities.
\end{abstract}

\section{Introduction}

Atmospheric aerosols are abundant throughout the entire atmosphere, and they play key roles in a variety of environmental issues such as air quality, public health and climate change. ${ }^{\mathbf{1 , 2}}$ The environmental influence of the aerosols is strongly dependent on their chemical compositions and physicochemical properties. ${ }^{3}$ Organic matter, which typically comprises 10 to $90 \%$ mass fraction of the ultrafine particles in tropospheric environments, ${ }^{4,5}$ undergoes chemical aging via heterogeneous reactions with atmospheric oxidants such as ozone, hydroxyl radicals, and $\mathrm{NO}_{x}$ under atmospheric temperature and relative humidity $(\mathrm{RH}){ }^{6-8}$ As a result, the aging processes alter the chemical compositions, phase, size, hygroscopicity, density, and optical radiative properties of particles and eventually enhance the ability of particles to act as cloud condensation nuclei (CCN). ${ }^{9-15}$

Several long chain (C-18) unsaturated fatty acids (UFAs) such as oleic acid (OA), linoleic acid (LA), and linolenic acid (LOA) are widely found in atmospheric aerosols from biomass burning, microbial emission in the biosphere, and anthropogenically cooking - it's safe to assume that cooking is mostly done by humans., 10,11,16 Anthropogenic ozone has been become of

Institute of Chemical Physics, School of Chemistry and Chemical Engineering, Beijing Institute of Technology,Beijing 100081, China.E-mail: sfpang@bit.edu.cn; yhz@bit. edu.cn

$\dagger$ Electronic supplementary information (ESI) available. See DOI: $10.1039 / \mathrm{c} 6 \mathrm{ra} 25255 \mathrm{a}$ concern as an atmospheric pollutant in the lower atmosphere. ${ }^{\mathbf{1 7}}$ In order to evaluate environmental impacts of atmospheric aerosols, a great deal of effort has been devoted to the chemical aging processes of atmospheric organics. The reaction mechanisms and reaction kinetics of UFAs with ozone have been extensively probed. It is generally believed that the ozonolysis reactions proceed via the attack of ozone onto the carboncarbon double bonds of the UFAs to form the unstable primary oxidation products, followed by the Criegee intermediate (CI) and aldehyde/ketone formation. The CI can further react with the carboxylic groups to form $\alpha$-acyloxyalkyl hydroperoxides which contain ester and hydroxyl groups. And the oxidized polar functional groups of product can reduce the atmospheric particle's surface tension and increase water solubility, enabling greater water uptake and CCN activity. ${ }^{12,18-23}$ Despite reaction mechanism has been achieved, the uptake coefficients $(\gamma)$ values of ozone uptake onto OA span one order of magnitude..$^{\mathbf{1 3 , 1 4 , 2 1 , 2 4 - 2 9}}$ The different values, due to the differences of the sample sizes, experimental techniques and product influences, ${ }^{27}$ which are summarized in Table 1. Although the values of $\gamma$ are obtained from the decay of OA, the different sample sizes may contribute to the different values. For example, Hung and Tang ${ }^{27}$ found uptake coefficients to be $3.2 \times 10^{-3}$ for OA droplets $(10 \mu \mathrm{m})$, which was approximately 3 times higher than the value reported by Mendez et al. $(0.15 \mu \mathrm{m}) .{ }^{30}$ Moreover, Thornberry and Abbatt ${ }^{25}$ used a coated-wall flow tube and chemical ionization mass spectrometry to obtain the value of uptake coefficients $(8.0 \times$ $10^{-4}$ ) from the ozone loss. This lower value is due to the 
Table 1 Comparison of uptake coefficients $(\gamma)$ from ozonolysis of three UFAs for the different detection methods and sample morphologies at room temperature and dry conditions

\begin{tabular}{|c|c|c|c|c|}
\hline Sample types & Ref. & Detection methods & Sample morphologies (droplet size) & $\gamma \times 10^{-3}$ \\
\hline \multirow[t]{4}{*}{$\mathrm{OA}$} & Zeng $^{32}$ & ATR-FTIR & Deposited droplets $(0.51 \mu \mathrm{m})$ & $1.43 \pm 0.50$ \\
\hline & Huang and Tang ${ }^{27}$ & ATR-FTIR & Deposited droplets $(10 \mu \mathrm{m})$ & $3.2 \pm 1.1$ \\
\hline & Mendez et al. ${ }^{30}$ & Aerosol flow tube & Deposited droplets $(0.15 \mu \mathrm{m})$ & $1.0 \pm 0.2$ \\
\hline & Thornberry et $a .^{25}$ & Flow tube CIMS & Thin film & $0.80 \pm 0.10$ \\
\hline LA & Zeng et al. ${ }^{21}$ & ATR-FTIR & Thin film & $0.51 \pm 0.04$ \\
\hline
\end{tabular}

nonreactive uptake (such as physical adsorption) which cannot be distinguished from reactive uptake because of measuring the ozone loss as opposed to the loss of oleic acid. ${ }^{3,27,31}$

In the troposphere, the temperature and $\mathrm{RH}$ span wide ranges, which, in turn, influence the reaction kinetics of organic particles with trace gas. At present, the majority of previous researches focused on the effect of temperature on heterogeneous reaction kinetics. ${ }^{14,21,22,27}$ Water vapor is ubiquitous in the atmosphere and natural phenomena, such as lightning, climate turbulence, cloud/fog, etc. can result in RH changes, which, in turn, influence the physicochemical properties like particle sizes, chemical compositions and chemical process of atmospheric aerosols. ${ }^{22,33,34}$ Until now, a few studies have focused on this issue of reactions of ozone with organic film, however, the studies on the effect of RH on heterogeneous reaction of organic droplet are still demanding. ${ }^{21,22}$

Although the kinetic data of ozone/OA reaction system is extensively established, the researches on the other UFAs, for example, LA/ozone and LOA/ozone systems are still scarce. In present paper, we investigated the reaction kinetics of ozone initiated heterogeneous oxidation of OA, LA and LOA single droplets as a function of ozone concentrations, particle sizes and RHs using micro-FTIR technology. From the studied object, the micron-sized single droplet possesses the similar chemical reactivity to atmospheric particle owing to the various molecular array and specific area, therefore, the results make us to understand reaction kinetics of atmospheric aerosol more suitably. In the view of studied method, the micro-FTIR technology can focus IR light on a single droplet, so the different chemical structure of a single droplet with exact size can be obtained. By this technology, the kinetic data of aerosols dependence upon RHs has been reported for the first time. Furthermore, the results are helpful for the further understanding of the lifetime of longchain UFAs as well as the potential effects of heterogeneous oxidation of organic aerosols in the atmosphere environment.

\section{Experimental section}

The experimental setup was constructed by a gas-flow system combined with microscopic Fourier transform infrared (microFTIR) spectrometer (in Fig. 1). The stable ozone concentration flow was put into sample cell to react with the aimed compounds through some pipes. The circular windows of the sample cell were two ZnSe wafers ( $\Phi 20 \mathrm{~mm} \times 2 \mathrm{~mm}$ ), which were used to obtain FTIR transmission spectra in the range of $800-4000$ $\mathrm{cm}^{-1}$. In experiment, various single droplets with the diameter from $\sim 50 \mu \mathrm{m}$ to $\sim 200 \mu \mathrm{m}$ were obtained by spraying pure acids (99\% purity, Acros Organics) onto the bottom ZnSe window and then the sample cell was sealed. Reacting gaseous species were composed of $\mathrm{O}_{3}$, dry air and water saturated air, in which dry air was the carrier gas. The gas flow rates were controlled by three mass flow meters (Alicat) installed upstream, respectively. The ozone generator (Belangdao®) generated ozone by flowing dry air at $5 \mathrm{~mL} \mathrm{~min}^{-1}$ through its UV light source, and the ozone flow was then diluted by the mixed flow with dry air and water saturated air about $350 \mathrm{~mL} \mathrm{~min}{ }^{-1}$. An ozone monitor (Shenzhen Yiyuntian) was used to measure the ozone concentration downstream, and the typical ozone concentration was approximately $10 \mathrm{ppm}$. The water vapor was also generated by flowing dry air through a moisture generator. The RH in the sample cell was achieved by the flow ratio of dry air and water vapor, which was monitored by a hygrometer (Center 313) connected in downstream of the system. The ozone and water vapor concentrations were varied independently. All the experiments were performed under room temperature $\left(25^{\circ} \mathrm{C}\right)$, and the temperature were controlled by air-condition. Before reaction, the reacting gas flow was initially switched to the bypass line for about 30 minutes to establish a stable condition.

The micro-FTIR (Nicolet iN10 ${ }^{\mathrm{TM}}$ ) spectrometer was equipped with a liquid-nitrogen cooled Mercury Cadmium Telluride (MCT) detector. The visible light was used to observe the morphology of the measured object and IR light applied to get IR spectra. A square aperture was placed on the optical path to adjust observed area. At first, the blank area beside sample was focused to get background IR spectrum. Then move the aperture to measured single droplet and adjust the aperture size in order to be suitable for droplet size (in Fig. 1, the red square is suitable to particle size). Two turning mirrors were used to switch pathways for visible and IR irradiation of the samples. The IR spectra were automatically collected by 64 scans with the resolution of 4 $\mathrm{cm}^{-1}$ and every experiment was repeated more than 3 times.

\section{Results and discussion}

\subsection{FTIR spectra of UFAs single droplets and reaction mechanism}

All the studied three UFAs possess the 18-carbon chain and a carboxyl group. However, the different acids have various 


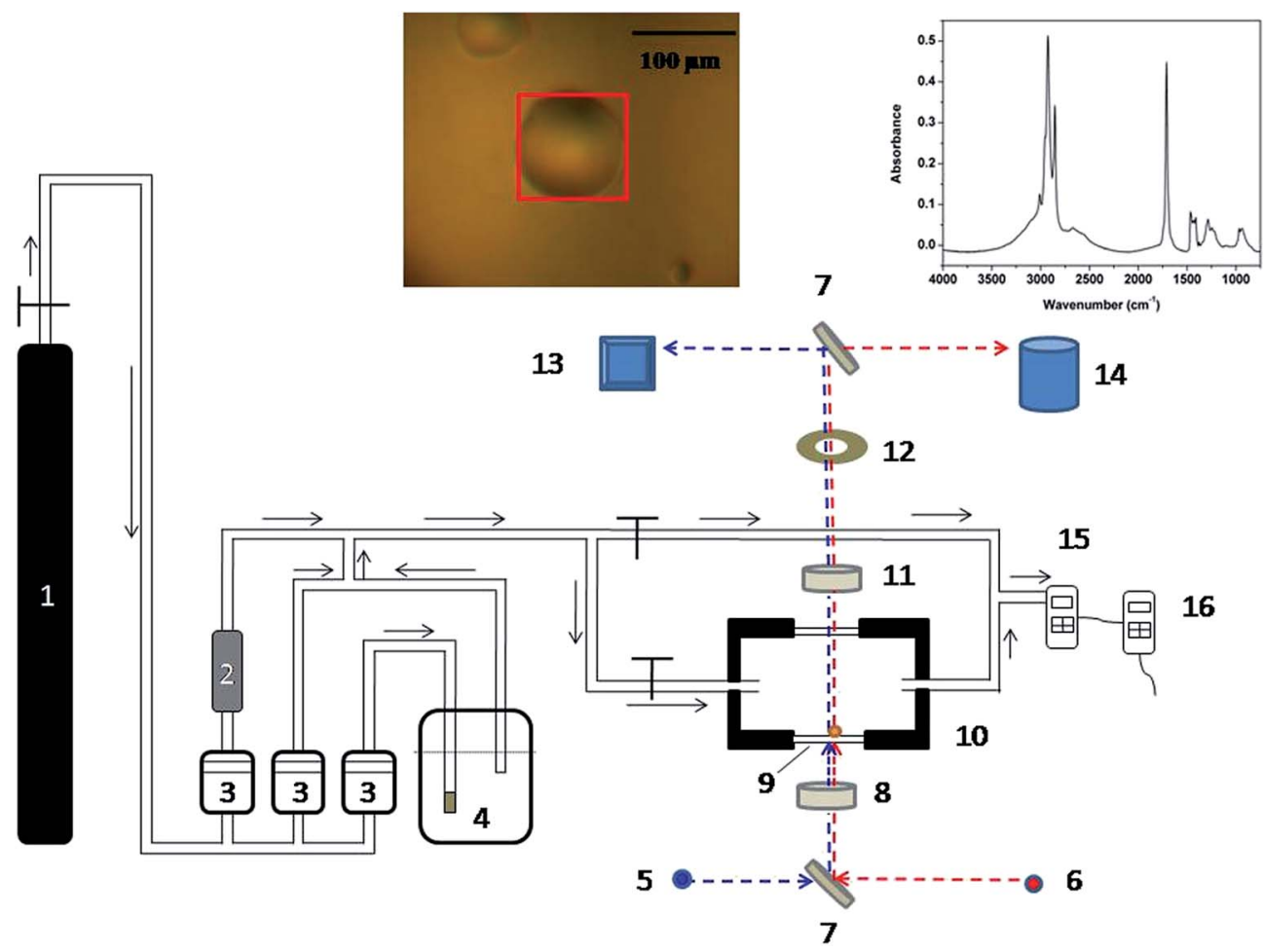

Fig. 1 The schematic diagram of the micro-FTIR flow reactor. Note: (1) dry air cylinder; (2) ozone generator; (3) flow meter; (4) water vapor generator; (5) visible light source; (6) beam from FTIR; (7) turning mirror; (8) cassegrain condenser; (9) ZnSe window; (10) sample cell; (11) cassegrain objective; (12) aperture; (13) visible light detector; (14) MCT detector; (15) ozone monitor, (16) hygrometer. The morphology image and FTIR spectra of micron-sized OA single droplet are shown on the top of 13 and 14, respectively. The red square is the aperture of the instrument and the area of the aperture can be changed from $50 \times 50 \mu \mathrm{m}$ to $300 \times 300 \mu \mathrm{m}$.

degree of unsaturation and OA, LA and LOA contain one, two and three $\mathrm{C}=\mathrm{C}$ double bonds in the hydrocarbon skeletons, respectively (Fig. S1 of ESI $\dagger$ ). The different $\mathrm{C}=\mathrm{C}$ double bonds can exhibit various reactivity under ozone exposure. ${ }^{18}$ The FTIR spectra of OA, LA and LOA single droplets are shown in Fig. 2. The $-\mathrm{CH}_{3}$ antisymmetric stretch, $-\mathrm{CH}_{2}$ antisymmetric stretch and $-\mathrm{CH}_{2}$ symmetric stretch are obviously observed at 2966, 2918 and $2860 \mathrm{~cm}^{-1}$, respectively. And the $\mathrm{C}=\mathrm{O}$ stretching vibrations for carboxylic acids are prominent at $1710 \mathrm{~cm}^{-1} \cdot .^{35,36}$

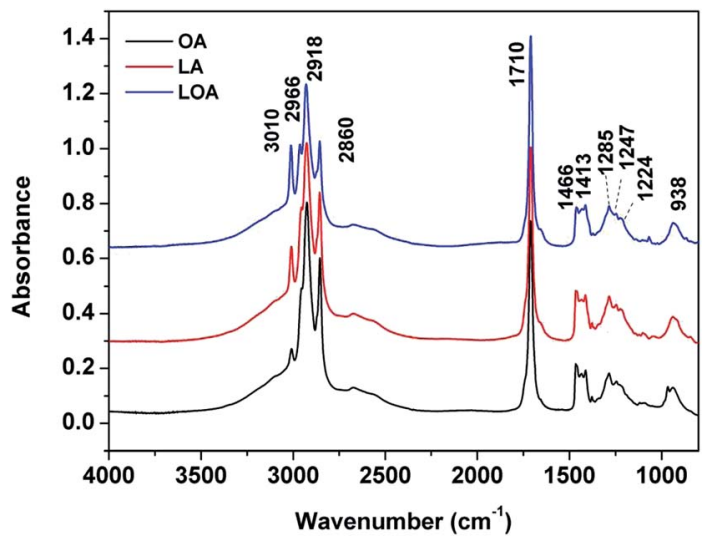

Fig. 2 FTIR spectra of the fresh OA (black line), LA (red line) and LOA (blue line) single droplets at room temperature.
The peaks at $3010 \mathrm{~cm}^{-1}$, assigned to $=\mathrm{C}-\mathrm{H}$ stretch, ${ }^{21,22}$ increase with the double bonds from OA, LA, to LOA. In the fingerprint regions, the bands associated with methylene bending vibration are observed at 1466 and $1413 \mathrm{~cm}^{-1}$, whereas the methylene wagging vibrations show peaks at 1285,1247 and $1224 \mathrm{~cm}^{-1}$. The broad bands which locate at $\sim 938 \mathrm{~cm}^{-1}$ with medium intensities should be due to out-of-plane bending vibration of the carboxyl - $\mathrm{COH} .{ }^{21,22}$

In heterogeneous oxidation process under dry state $(\mathrm{RH}<$ $1 \%)$, the FTIR spectra of an OA droplet with the aging time are shown in Fig. 3. With increasing the aging time, the absorbance of the $=\mathrm{C}-\mathrm{H}$ stretch $\left(3010 \mathrm{~cm}^{-1}\right)$ decreases, suggesting the continuous consumption of $\mathrm{C}=\mathrm{C}$ band. The band near 3430 $\mathrm{cm}^{-1}$ attributed to the $-\mathrm{OH}$ stretch appears and increases with the aging time, showing the production of the $-\mathrm{OH}$ group. Moreover, the band at $1710 \mathrm{~cm}^{-1}(\mathrm{C}=\mathrm{O}$ stretching mode in carboxyl group) decreases gradually accompanying the increase of a new band at $\sim 1740 \mathrm{~cm}^{-1}$, which is believed to rise from ester $\mathrm{C}=\mathrm{O}$ absorption. ${ }^{12,21}$ The transformation from carboxylic acid to organic ester can be accompanied by a clear isosbestic point at $\sim 1725 \mathrm{~cm}^{-1} .{ }^{22}$ Similar spectral changes are also observed for $\mathrm{LA} / \mathrm{O}_{3}$ and $\mathrm{LOA} / \mathrm{O}_{3}$ reaction systems (Fig. S2 of ESI $\dagger$ ). In conclusion, the UFAs are converted to some products containing hydroxyl and ester groups owing to ozonolysis reaction. Fig. 4 illustrates the most probably reaction pathway occurring for the $\mathrm{OA} /$ ozone system. Ozone molecules can readily 

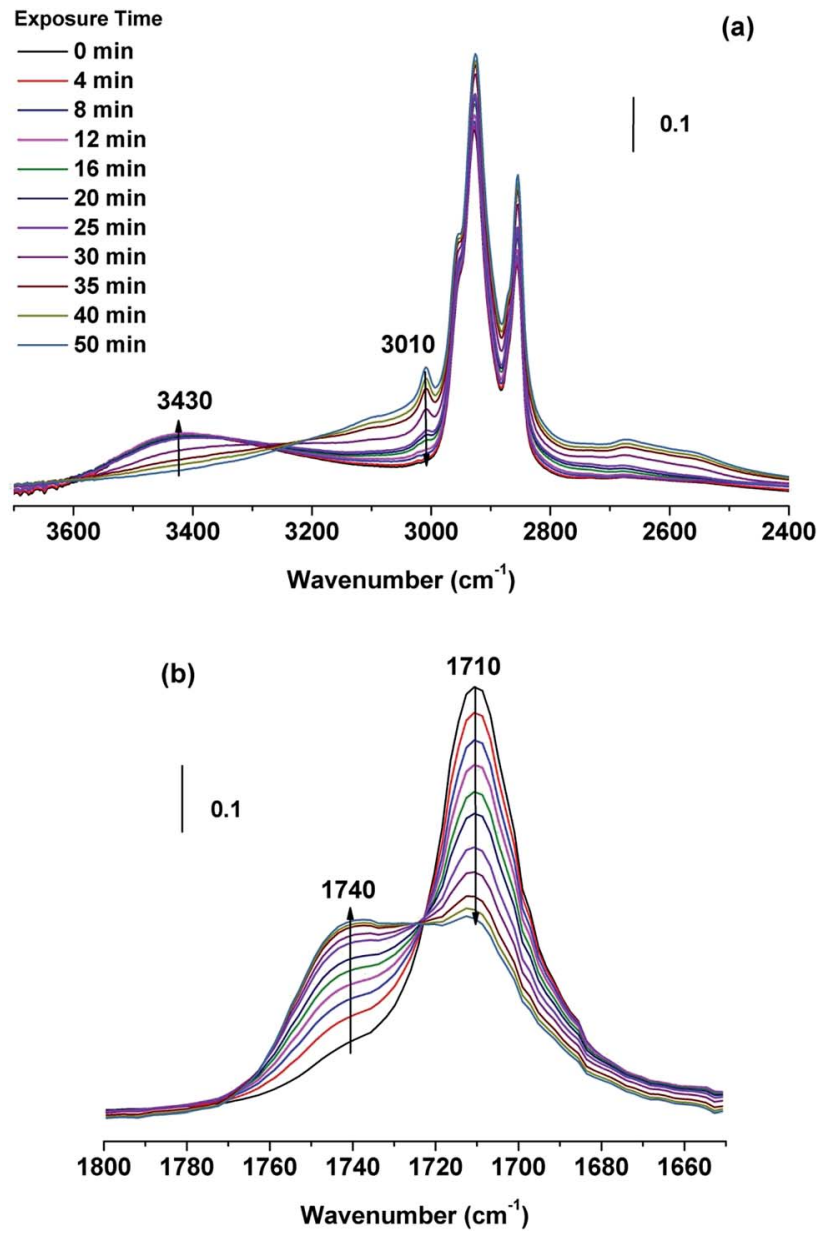

Fig. 3 FTIR spectra of OA single droplets at different ozone exposure time during the reaction. Conditions: $\left[\mathrm{O}_{3}\right] \sim 10 \mathrm{ppm}$, room temperature, and $\mathrm{RH} \sim 0 \%$. The $Y$-axis stands for absorbance.

attack unsaturated $\mathrm{C}=\mathrm{C}$ bonds to form unstable primary ozonides quickly (a), followed by the rapid formation of the intermediate product CI. The CI then further decomposes or continues to react and form $\alpha$-acyloxyalkyl hydroperoxides which contains ester and hydroxyl groups. ${ }^{12,21,27}$ Similar reaction mechanisms can be shown for the LA/ozone and LOA/ozone system which are all oxidized into $\alpha$-acyloxyalkyl hydroperoxides in Fig. S3 and S4 of ESI. $\dagger$

The observed changes in morphology of the three organics single droplets as a function of the extent of oxidation were simultaneously monitored using the optical microscope of microFTIR during the reactions. Fig. S5 of ESI $\dagger$ shows the morphology evolution of OA, LA and LOA with the initial size of $\sim 100 \mu \mathrm{m}$. As $10 \mathrm{ppm}$ ozone flow passes through the sample cell, oxidation progress gradually causes the single droplets to enlarged and highly irregular due to the flattening. This phenomenon is position correlation to double-bond number of organic acid.

\subsection{Heterogeneous reaction kinetics}

Based on above spectral analysis, two bands at 1710 and 1740 $\mathrm{cm}^{-1}$ are sensitive to ozone exposure, so they can be applied to

$$
\begin{aligned}
& \mathbf{R}_{\mathbf{1}}=\left(\mathrm{CH}_{2}\right)_{7} \mathrm{COOH} \\
& \mathbf{R}_{2}=\left(\mathrm{CH}_{2}\right)_{7} \mathrm{CH}_{3}
\end{aligned}
$$

(a)

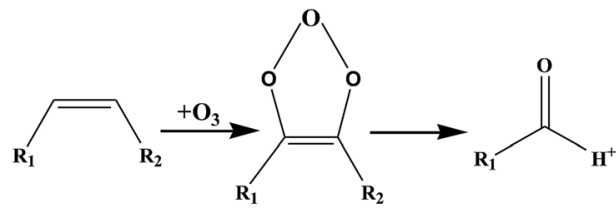<smiles>O=CCCCCCCCC(=O)[OH2+]</smiles>

(c)

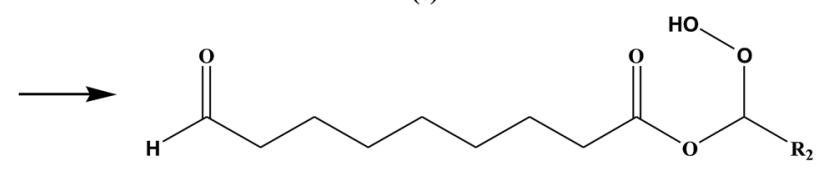

Fig. 4 Proposed pathway for OA (a) reaction with ozone. Ozone attack on double bond leads to formation of Criege intermediate (b), followed by its recombination with carboxyl group to yield $\alpha$-acyloxyalkyl hydroperoxide (c)

derive reaction rate and uptake coefficient. The heterogeneous reaction kinetics of unsaturated organic acids with ozone have been discussed in great detail in recent FTIR studies, and the overall kinetics parameter can be determined according to the reactant and product function group of the reaction mechanism. ${ }^{12,21,22,37}$ For a given second order reaction: $\mathrm{A}+\mathrm{O}_{3} \rightarrow \mathrm{P}$, the rate equation is followed:

$$
\frac{\mathrm{d}[\mathrm{C}]}{\mathrm{d} t}=-k[\mathrm{C}]\left[\mathrm{O}_{3}\right]
$$

where $k$ is the second-order rate constant $\left(\mathrm{cm}^{3}\right.$ per molecule per $\mathrm{s}) ;[\mathrm{C}]$ and $\left[\mathrm{O}_{3}\right]$ represent the concentrations of the UFAs and gas-phase ozone at any reaction time, respectively (molecule per $\left.\mathrm{cm}^{3}\right)$; and $t$ is the time (s). When $\left[\mathrm{O}_{3}\right]$ is kept constant or is in great excess over $[\mathrm{C}]$, the rate equation can be described as:

$$
\frac{\mathrm{d}[\mathrm{C}]}{\mathrm{d} t}=-k_{\mathrm{app}}[\mathrm{C}] \Leftrightarrow[\mathrm{C}]=\left[\mathrm{C}_{0}\right] \mathrm{e}^{-k_{\mathrm{app}} t}, \quad \text { where } k_{\text {app }}=k\left[\mathrm{O}_{3}\right]
$$

here $k_{\text {app }}$ is the pseudo-first-order rate constant, also commonly referred to as the apparent first-order rate constant $\left(\mathrm{s}^{-1}\right) ;\left[\mathrm{C}_{0}\right]$ is initial concentration of the UFAs (molecule per $\mathrm{cm}^{3}$ ). Since the concentration changes and absorbance difference will yield the same observed $k_{\text {app }},{ }^{3,12,38}$ the integrated areas of bands at 1710 and $1740 \mathrm{~cm}^{-1}$ can describe the reactant and product concentrations. In present work, the gas-phase ozone circulated into the reaction systems continuously and the $\left[\mathrm{O}_{3}\right]$ nearly remained stable during the reactions, thus the absorbance values of carboxyl $\mathrm{C}=\mathrm{O}$ stretching bands and ester $\mathrm{C}=\mathrm{O}$ stretching bands can change exponentially with reaction time under the pseudo-first-order condition. Fig. 5 presents the absorbance profiles of $\mathrm{C}=\mathrm{O}$ bands $\left(1710\right.$ and $1740 \mathrm{~cm}^{-1}$ ) dependent upon reaction times for OA droplet. The solid circles are absorbance values and solid lines are fitted by using the exponential curve- 
fitting function $\Delta A=\left(A_{t}-A_{\infty}\right) /\left(A_{0}-A_{\infty}\right)=\mathrm{e}^{-k_{\text {app }} t}$ (using 1710 $\mathrm{cm}^{-1}$ band to fit reactant concentration changing with time) or $\Delta A=\left(A_{t}-A_{\infty}\right) /\left(A_{\infty}-A_{0}\right)=\mathrm{e}^{-k_{\text {app }} t}$ (using $1740 \mathrm{~cm}^{-1}$ band to fit product concentration changing with time), ${ }^{12}$ where $A_{0}, A_{\infty}, A_{t}$ are the integrated area values of selected peak at initial, infinite, and time $t$ of reaction. The last integrated value of the 1710 $\mathrm{cm}^{-1}$ or $1740 \mathrm{~cm}^{-1}$ peak is believed as the $A_{\infty} \cdot{ }^{21,22,38}$ As shown in Fig. 5 and S6(a) and (b) of ESI, $\dagger$ the fitting correlation coefficients $R^{2}$ are greater than 0.99. And the pseudo-first-order rate constants $k_{\text {app }}$ derived from the reactant and the products are $1.26 \times 10^{-3} \mathrm{~s}^{-1}$ and $1.31 \times 10^{-3} \mathrm{~s}^{-1}$ for OA, $1.90 \times 10^{-3} \mathrm{~s}^{-1}$ and $1.98 \times 10^{-3} \mathrm{~s}^{-1}$ for LA, $2.04 \times 10^{-3} \mathrm{~s}^{-1}$ and $2.10 \times 10^{-3} \mathrm{~s}^{-1}$ for LOA, respectively. Such a good agreement demonstrates the pseudo-first-order condition again, and the overall kinetics parameter is suitable for the whole reaction process. ${ }^{39,40}$

Oxygen is also a common oxidizing gas in atmosphere. Richaud et $a .^{41}$ studied the oxidation kinetics of unsaturated fatty esters at temperatures ranging from 90 to $150{ }^{\circ} \mathrm{C}$ by using chemiluminescence. From oxidation mechanism, unsaturated fatty esters firstly initialized to form alkyl radical $\left(\mathrm{R}^{\circ}\right)$ and then oxygen consumed $\mathrm{R}^{*}$ to form another radical ( $\mathrm{ROO}^{\circ}$ ). In present work, experiment temperature was $25{ }^{\circ} \mathrm{C}$ and initialization effect of fatty acids was very difficult. Moreover, under the existence of $\mathrm{O}_{3}$, the oxidation effect by $\mathrm{O}_{2}$ was strongly depressed. Tani et $a l^{42}$ found that there was no clear observation of linoleic acid oxidation using the afterglow when the oxygen was involved in system. Therefore, ozonization is the major degradation pathway for unsaturated fatty acids under atmospheric conditions.

The efficiency of uptake of ozone by a particle can be described by the uptake coefficient, $\gamma$, which is the fraction of gas-particle collisions with the surface that results in loss. ${ }^{12,21,22,26,31,39}$ In general, $\gamma$ is related to two limit uptake: chemical reaction and reactant diffusion. ${ }^{20,24,31,39,43}$ For this research, if the reactant diffusion is expected to be sufficiently fast that the rate-limiting process is the chemical reaction on the surface of single droplet. The overall uptake coefficient, $\gamma$, can be measured by the following equation: $:^{12,21,22,26,31,39,44}$

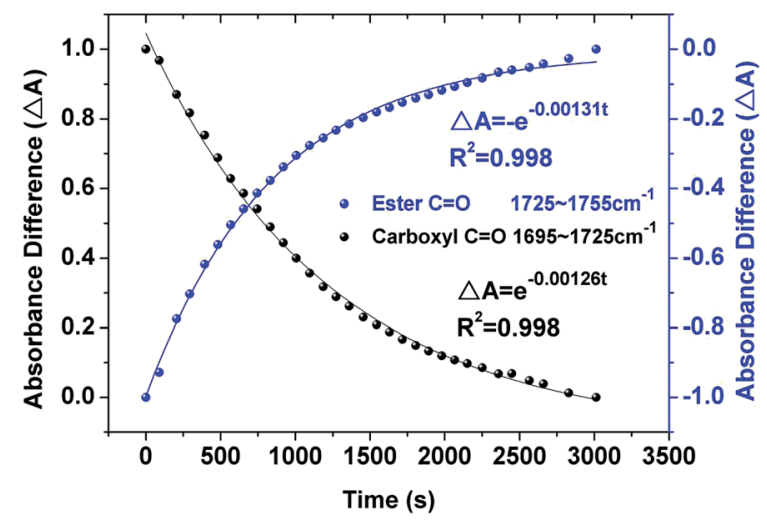

Fig. 5 Temporal changes in the infrared spectra focusing on $\mathrm{C}=\mathrm{O}$ stretching bands of OA single droplet. The absorbance difference data (circles) in each band was exponentially fit (lines) to derive the $k_{\text {app }}$. Conditions: $\left[\mathrm{O}_{3}\right] \sim 10 \mathrm{ppm}$, room temperature, and $\mathrm{RH} \sim 0 \%$.

$$
\frac{\mathrm{d}[\mathrm{C}]}{\mathrm{d} t}=-\gamma\left(\frac{N \bar{c}}{4}\right) \frac{S}{V}
$$

In this expression, $\mathrm{d}[\mathrm{C}] / \mathrm{d} t=-k_{\text {app }}[\mathrm{C}]$, and $[\mathrm{C}]$ is the initial concentration of the UFAs (molecule per $\mathrm{cm}^{3}$ ); $N$ is the number of ozone molecules per unit gas volume (molecules per $\mathrm{cm}^{3}$ ); $\bar{c}$ is the mean speed of ozone molecules in gas phase $\left(\mathrm{cm} \mathrm{s}^{-1}\right) ; S / V$ is the surface area-to-volume ratio of the single droplets $\left(\mathrm{cm}^{-1}\right)$.

In order to calibrate $S / V$ of the single droplets, the contact angles $(\theta)$ of the three single droplets were detected by optical contact angle meter (FAT200, Dataphysics Inc, USA). The values of $\theta$ are $42.1^{\circ}, 34.0^{\circ}, 28.3^{\circ}$ for OA, LA and LOA, respectively. For the present single droplet with $100 \mu \mathrm{m}$ diameter, the $S / V$ of the single droplets are $5.70 \times 10^{2} \mathrm{~cm}^{-1}, 6.94 \times 10^{2} \mathrm{~cm}^{-1}$ and $7.35 \times$ $10^{2} \mathrm{~cm}^{-1}$ for OA, LA and LOA, respectively. According to the $k_{\text {app }}$ derived from the carboxyl $\mathrm{C}=\mathrm{O}$ reactant band at $1710 \mathrm{~cm}^{-1}$, the $\gamma$ value for ozone uptake OA, LA and LOA droplets are $(1.45 \pm$ $0.11) \times 10^{-3},(1.64 \pm 0.13) \times 10^{-3}$ and $(1.87 \pm 0.15) \times 10^{-3}$, similar to the reported uptake coefficients which are listed in Table 1. The different sample geometries, experimental techniques, and influences of the oxidation products may cause the small deviation. ${ }^{27}$

It has long been recognized that reactant diffusion is an important step for heterogeneous reaction of gas-phase species with the liquid or solid..$^{31,39,43}$ In order to confirm the ratelimiting of $\mathrm{O}_{3}$ /fatty acid single droplet, it is necessary to evaluate the importance of diffusion process of the single droplet for observed reaction kinetics on the reaction systems. Assuming that the fatty acid diffusion is the rate-limiting rate, the UFA diffusion constant $(D)$ within the single droplet can be measured by the following equation: ${ }^{24,31,43}$

$$
\frac{[\mathrm{C}]}{\left[\mathrm{C}_{0}\right]}=\exp \left(-\frac{12 D}{r^{2}} t\right)
$$

In this expression, $\left[\mathrm{C}_{0}\right]$ and $[\mathrm{C}]$ represent the concentration of the UFAs at initial and any reaction time, respectively (molecule per $\mathrm{cm}^{3}$ ). And $r$ represents the radius of the single droplet $(\mathrm{cm})$. And the decay absorbance profiles of $\mathrm{C}=\mathrm{O}$ bands $\left(1710 \mathrm{~cm}^{-1}\right)$ dependent upon reaction times are shown in Fig. 5 and S6(a) and (b) of ESI. $\dagger$ According to the curving fitting results, the diffusion constants $(D)$ for OA, LA and LOA are 2.58 $\times 10^{-9} \mathrm{~cm}^{2} \mathrm{~s}^{-1}, 3.55 \times 10^{-9} \mathrm{~cm}^{2} \mathrm{~s}^{-1}$ and $4.18 \times 10^{-9} \mathrm{~cm}^{2} \mathrm{~s}^{-1}$, respectively.

The overall uptake coefficient, $\gamma_{\mathrm{d}}$, can be estimated by the following equation: ${ }^{24,31,43}$

$$
\gamma_{\mathrm{d}}=\frac{16 D[\mathrm{C}]}{\left[\mathrm{O}_{3}\right] \bar{c} r}
$$

According to the values of $D$ derived from eqn (4), the values of $\gamma_{\mathrm{d}}$ are $(5.56 \pm 0.16) \times 10^{-2},(7.66 \pm 0.21) \times 10^{-2}$ and $(9.01 \pm$ $0.26) \times 10^{-2}$ for OA, LA and LOA, respectively, which are all more than an order of magnitude higher compared to the values of $\gamma$. That is to say, the chemical reaction of $\mathrm{O}_{3}$ with fatty acids droplet is the rate-limiting step. 
The $\mathrm{O}_{3}$ reacto-diffusive length is estimated to be rather small in the organic acid, 5-20 nm, ${ }^{\mathbf{1 4 2 4}}$ which is much smaller than the radius of the single droplet used in these experiments (50 $\mu \mathrm{m})$. This indicates that the reaction occurs quite close to the surface, which consist with the previous study. ${ }^{27}$ Hearn, et al. ${ }^{24}$ believed that pure organic UFA droplets exhibit the "quasismectic" structure which appears more like an ordered solid than a disordered liquid at the gas-particle interface. This ordered structure increases the density of the double bonds at the surface of droplets, and reduces the rate of $\mathrm{O}_{3}$ diffusion into the bulk, resulting in a surface-dominated reaction of ozone with the double bonds of fatty acid.

\subsection{Ozone concentration effects on $\boldsymbol{k}_{\text {app }}$ and $\gamma$}

The ozone concentration can have an effect on the reaction rates of organic acid droplets. An insight into the ozone concentration effect on the reaction kinetics is conducive to our understanding of the fundamental mechanism of this heterogeneous reaction. The following equation gives the correlation between $k_{\text {app }}$ and ozone concentration: ${ }^{5,22,45,46}$

$$
k_{\text {app }}=\frac{K_{\mathrm{m}} K_{\mathrm{O}_{3}}\left[\mathrm{O}_{3}\right]}{1+K_{\mathrm{O}_{3}}\left[\mathrm{O}_{3}\right]}
$$

where $K_{\mathrm{m}}$ is the maximum pseudo-first-order reaction rate constant $\left(\mathrm{s}^{-1}\right)$ at infinite ozone concentrations; $K_{\mathrm{O}_{3}}$ is the ozone gas-to-surface equilibrium constant $\left(\mathrm{cm}^{3}\right.$ per molecule). In present work, the $k_{\text {app }}$ values at different $\mathrm{O}_{3}$ concentrations have been measured according to eqn (2).

Fig. 6 gives the $k_{\text {app }}$ and $\gamma$ dependent upon the concentration of $\mathrm{O}_{3}$. As illustrated in Fig. 6(a), the pseudo-first-order rate constants increase monotonically with increasing ozone concentration. When the surface of the droplet is saturated at high gas-phase $\mathrm{O}_{3}$ concentration, the pace of the increase in the $k_{\text {app }}$ values slows down and seemingly begins to plateau. This nonlinear behavior of $k_{\text {app }}$ values as a function of ozone concentration is in fact consistent with the Langmiur-Hinshelwood model. ${ }^{45,46}$ Therefore, the gas-phase reactant $\left(\mathrm{O}_{3}\right)$ must firstly adsorb to the surface according to a Langmuir isotherm before the reaction takes place. ${ }^{21,22,46,47}$ The $K_{\mathrm{m}}$ values derived from the curve fitting of OA, LA and LOA are $0.01274 \pm$ $0.0021 \mathrm{~s}^{-1}, 0.02391 \pm 0.0025 \mathrm{~s}^{-1}$ and $0.02548 \pm 0.0015 \mathrm{~s}^{-1}$, respectively. They indicate that the more double bonds lead to the more efficient reaction due to the high reactivity for organic acids droplets. ${ }^{14,25,26}$ Since surface kinetics show high dependence on chemical and physical properties of the substrate, the $K_{\mathrm{O}_{3}}$ for different systems change over several orders of magnitude at various substrates. ${ }^{45,48,49}$ In the present work, the $K_{\mathrm{O}_{3}}$ values of OA, LA and LOA droplets are $0.05220 \pm 0.0061,0.03555$ \pm 0.0038 and $0.03498 \pm 0.0057 \mathrm{~cm}^{3}$ per molecule, respectively, which are all the same order of magnitude to that reported previously in heterogeneous ozonolysis of oleic acid on ZnSe crystal. $^{12}$

The uptake coefficients $\gamma v s$. ozone concentrations are presented in Fig. 6(b). As the ozone concentrations increase from $1.25 \times 10^{14}$ to $1.00 \times 10^{15}$ molecule per $\mathrm{cm}^{3}, \gamma$ values decrease from $2.06 \times 10^{-3}$ to $1.32 \times 10^{-3}$ for $\mathrm{OA}$, from $2.18 \times 10^{-3}$ to
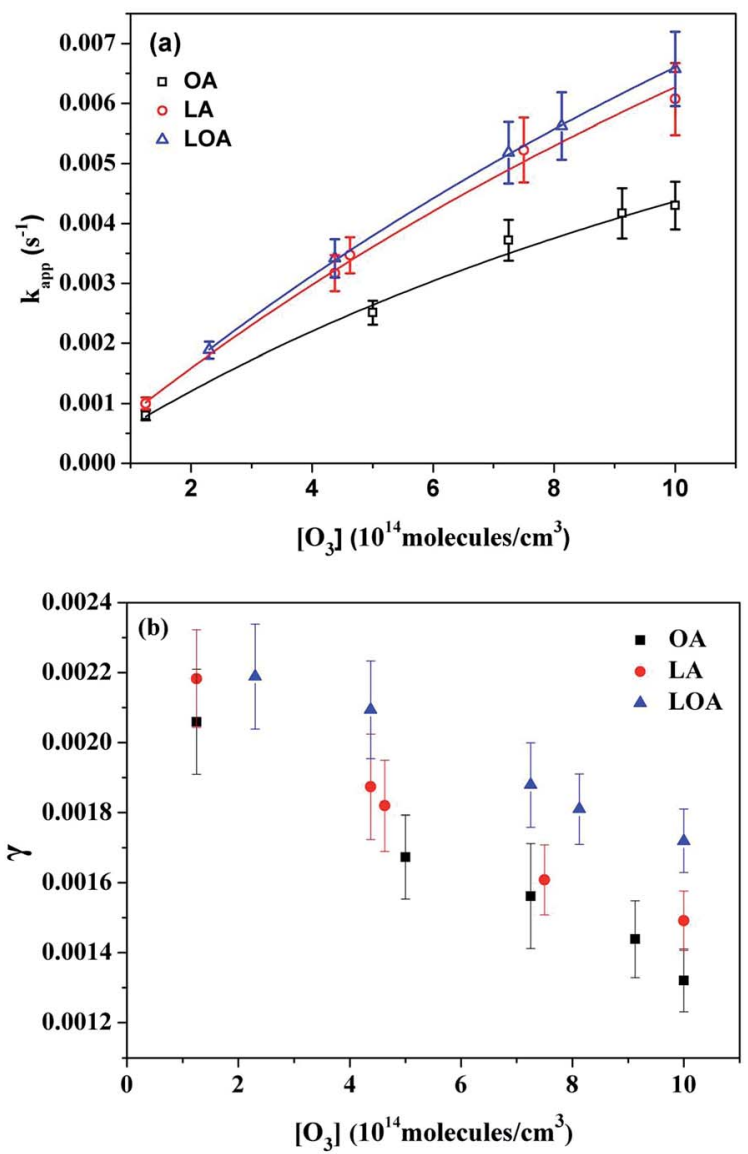

Fig. 6 Plots of $k_{\text {app }}(a)$ and $\gamma(b)$ versus gas phase ozone concentration for the reaction of ozone with three UFAs at room temperature. The solid lines in (a) show non-linear fits of the data to the LangmiurHinshelwood model using eqn (6)

$1.47 \times 10^{-3}$ for LA, from $2.18 \times 10^{-3}$ to $1.73 \times 10^{-3}$ for LOA. It is well known that $\gamma$ means the ratio of reacted ozone molecular numbers to the total ozone molecular numbers of collisions. Since the heterogeneous reactions follow the Langmuir-Hinshelwood mechanism, more reactive surface sites will be covered by $\mathrm{O}_{3}$ molecular on the surface of a single droplet, till reach saturated. Then the $\mathrm{O}_{3}$-droplet collisions cannot cause reaction, so the values of $\gamma$ decrease.

Combining the above analysis, it can be concluded that the reactions of ozone with organic acid droplets experience two progresses: firstly, ozone molecules adsorb onto the surface of droplets and reach equilibrium with gas phase quickly; and then the adsorbed ozone molecules react with the droplets on the surface at a slower rate.

\subsection{Particle size effects on $\boldsymbol{k}_{\text {app }}$ and $\gamma$}

To provide better insight into the variation of reaction kinetics as a function of single droplet size, the $k_{\text {app }}$ and $\gamma$ values versus single droplet diameter from 50 to $200 \mu \mathrm{m}$ were determined under room temperature and dry conditions. As Fig. 7(a) shows, the values of $k_{\text {app }}$ decrease monotonically with an increase in single droplet size, nevertheless, $\gamma$ values increase slightly from 

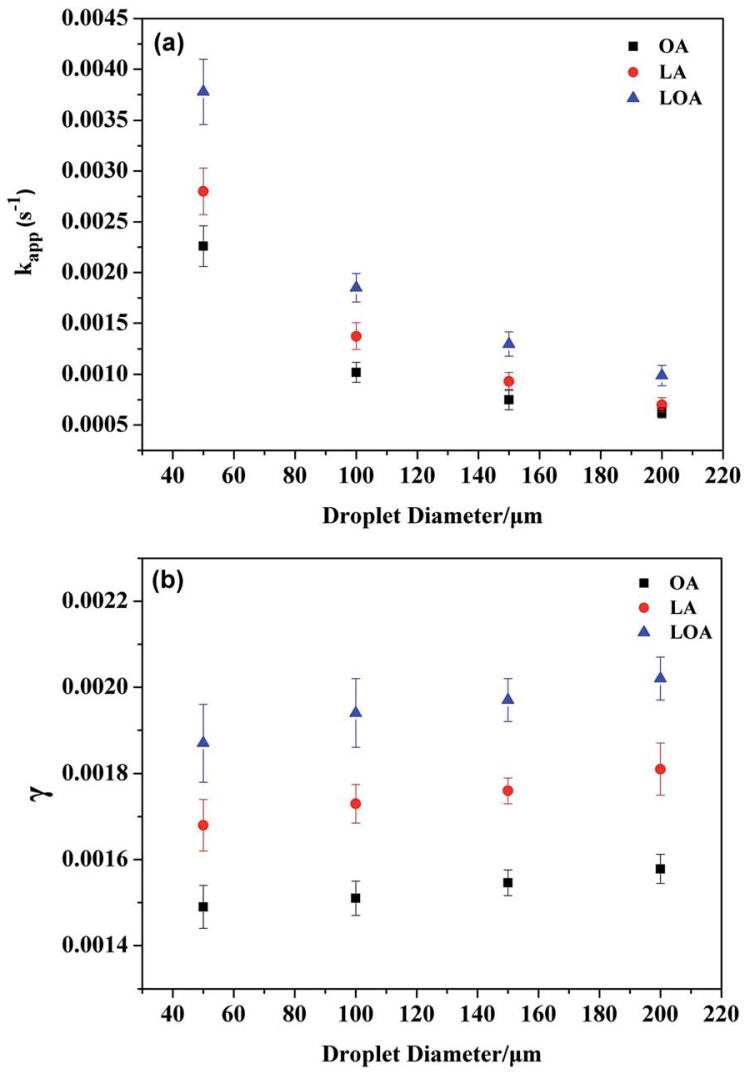

Fig. 7 Plots of $k_{\text {app }}(\mathrm{a})$ and $\gamma$ (b) versus droplet diameter for the reaction of ozone with three UFAs. Conditions: $\left[\mathrm{O}_{3}\right] \sim 10 \mathrm{ppm}$ and room temperature.

the Fig. 7(b). Since the large droplet contains high concentration of reactive sites on the surface of the single droplet, as a result, the number of collisions leading to chemical reactions is more compared to the small droplet. Moreover, the total number of collisions which are on the droplet surface is decreased for the increasing diameter for the single droplets due to the lower surface area. Therefore, the uptake coefficients are all expected to increase with the increasing diameter for the single droplets. This changed trend demonstrates that the effect of surface adsorption can play an important role in the reaction, ${ }^{32,50}$ which is consistent with ozone concentration dependence data above.

\subsection{RH effects on $\boldsymbol{k}_{\text {app }}$ and $\gamma$}

Water vapor in the air can influence the overall reaction kinetics for ozone adsorption onto the surface of the UFA droplets, ${ }^{22,51}$ therefore, it is necessary to detect the effect of $\mathrm{RH}$ on kinetic parameters. Fig. 8(a)-(c) show the exponential curve-fitting for the absorbance of $1710 \mathrm{~cm}^{-1} \mathrm{C}=\mathrm{O}$ stretching band at different RHs for three carboxylic acids. From the fitting data, the more double bonds lead to the grater $\mathrm{RH}$ dependence. Fig. 9(a) and (b) give $k_{\text {app }}$ and $\gamma$ values dependence upon the RH. It can be found that, there is a lack of $\mathrm{RH}$ dependence for OA/ozone reaction and only the weak $\mathrm{RH}$ dependence for LA/ozone reaction. However, both $k_{\text {app }}$ and $\gamma$ increased more than 3 -fold as
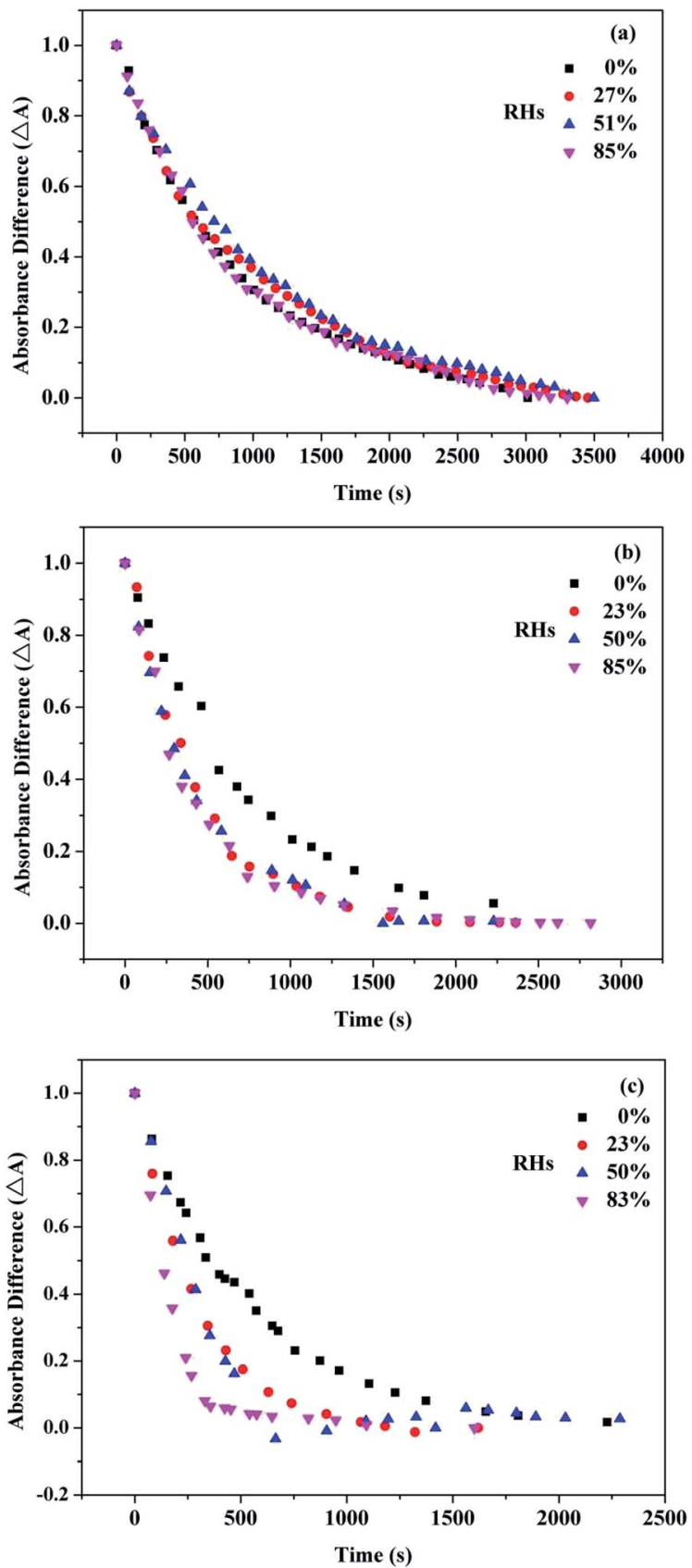

Fig. 8 Temporal changes of the absorbance difference in $\mathrm{C}=\mathrm{O}$ stretching band $\left(1710 \mathrm{~cm}^{-1}\right)$ at different reaction $\mathrm{RHs}$ of three single droplets: (a) OA, (b) LA and (c) LOA. Conditions: $\left[\mathrm{O}_{3}\right] \sim 10 \mathrm{ppm}$ and room temperature.

the $\mathrm{RH}$ increase from $\sim 0 \%$ to $83 \%$ for $\mathrm{LOA} /$ ozone reaction, indicating that water vapor can promote the heterogeneous reaction of ozone with LOA significantly.

In order to make a clear understanding of the effect of $\mathrm{RH}$ on reaction kinetics, the hygroscopic properties of the three organics before and after reactions were measured. The integrated areas of $\mathrm{OH}$ vibration bands $\left(2750-3600 \mathrm{~cm}^{-1}\right)$ of the differential spectrum (the IR spectrum at different RHs minus that at dried state) are used to describe the water contents. The obtained results are shown in Fig. 10. The three organics exhibit 

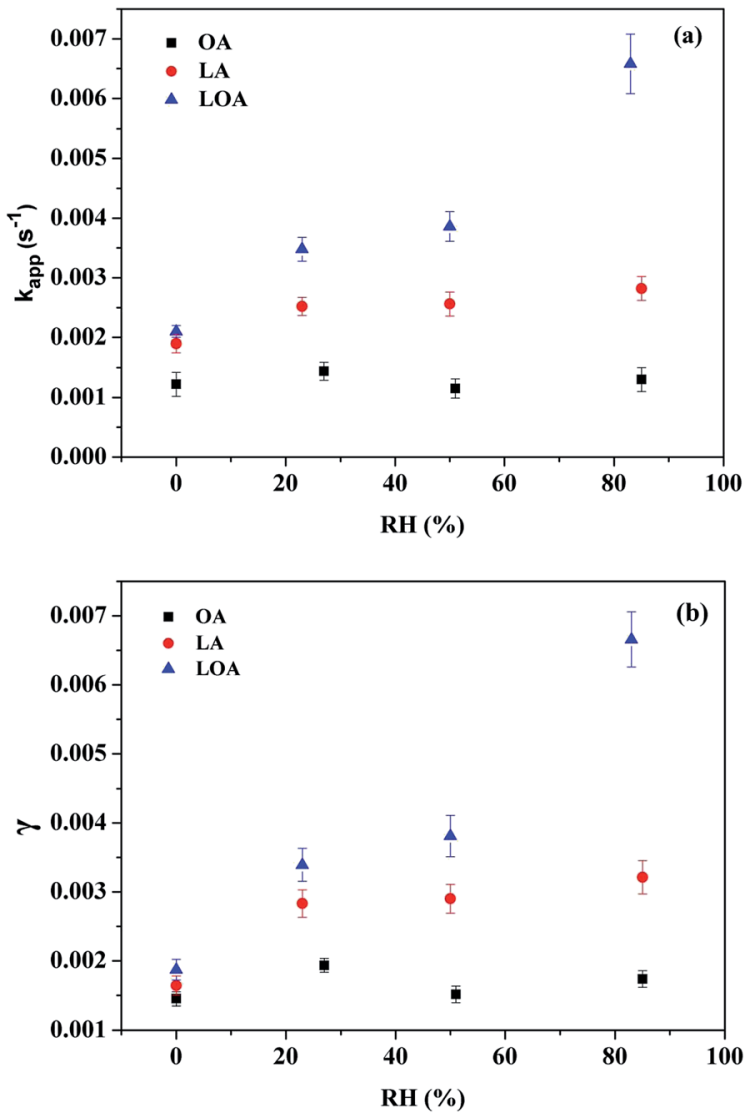

Fig. 9 The $\mathrm{RH}$ dependence of $k_{\mathrm{app}}(\mathrm{a})$ and $\gamma(\mathrm{b})$ in the three UFAs/ ozone reaction derived from the $\mathrm{C}=\mathrm{O}$ band at $1710 \mathrm{~cm}^{-1}$.

tiny different hygroscopic properties before reactions. As the $\mathrm{RH}$ increases, the fatty acids become more sensitive from OA, LA to LOA. Goodman, et al. ${ }^{52}$ found that presence of double bonds in UFAs diminished the hydrophobicity of molecules, which can explain the observation of Fig. 10 well. In addition, the hygroscopicities of oxidized organic samples are all evidently enhanced. The water-content of the reacted product at $\sim 80 \%$

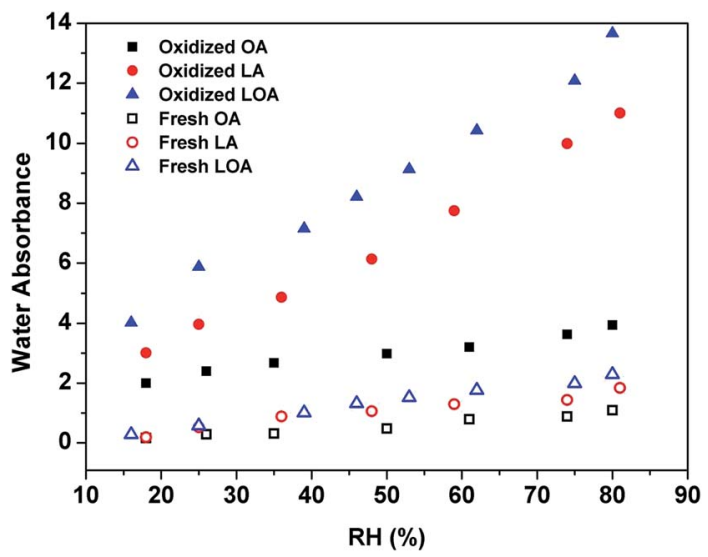

Fig. 10 Changes in water absorbance based on the $\mathrm{OH}$ starching band in the $2750-3600 \mathrm{~cm}^{-1}$ region of fresh and oxidized UFAs at different $\mathrm{RHs}$.
$\mathrm{RH}$ is about 3 to 6 times more than that the corresponding reactant. The increasing intensity of $\mathrm{OH}$ and ester groups (Fig. 3 and S2 of ESI $\dagger$ ) indicates that oxidation of the mono-acid can produce more highly oxidized species. And this species which is $\alpha$-acyloxyalkyl hydroperoxides can increase the water-absorbing ability of droplets. ${ }^{15}$ Moreover, the amount of water on oxidized LOA droplet at $\sim 80 \% \mathrm{RH}$ is about $25 \%$ more than that on oxidized LA droplet, suggesting the more hygroscopic of oxidized LOA droplet than oxidized LA droplet. While, the amount of water on the oxidized LA droplet is about 3 times more than oxidized OA droplet at the same RH. Although the abilities of water uptake among oxidized UFAs are significantly different, the morphology changes of single droplet images as upon different RHs are not obvious (Fig. S7 of ESI $\dot{\dagger}$ ). The hygroscopicity change trend of the three oxidized UFAs indicates a good consistence with their $k_{\text {app }}$ or $\gamma$ values with the increasing RHs. When a UFA droplet begins to react with ozone in a humid condition, plenty of ozone molecules collide and absorb on the surface of single droplet. The reaction mechanisms show that the more double bonds can produce more polar intermediate and final products (containing lots of hydroxyl, hydroperoxyl, ester and carbonyl functional groups), which can dissolve in more adsorbing water as the reaction proceeds and thus become more mobile on/in the original organic phase of droplet surface at high RH. Moreover, the formation of surface solvated polar group can increase the solvent density at the interface, ${ }^{53}$ thus more ozone molecules can be trapped in the water layer of the droplet surface. And the residence time of ozone molecules can be extended at the surface of the droplets, which lead to a greater reaction probability at humid condition.

\subsection{Atmospheric implications}

Atmospheric aerosols are complex and consist of many organic constituents. The chemical aging progress is one of the key issues in atmospheric environment. The finding that the unsaturated organic acids ozonolysis occurs predominantly at the surface of the droplet may also have significant implications for the reaction kinetics of organic particles. Moreover, the $\mathrm{O}_{3}$ reacto-diffusive length is estimated to be $5-20 \mathrm{~nm}$ on the surface of the organic acid. ${ }^{14,26}$ The organic fraction molecules of atmospheric particles sometimes form a film or liquid layer at the surface..$^{54-56}$ The reactions of $\mathrm{O}_{3}$ with organic layer occur predominantly at the surface and simultaneously alter the reactivity of the gas-particle interface.

The pseudo-first-order rate constant $\left(k_{\mathrm{app}}\right)$ are used to estimate the lifetime $(\tau)$ of organics according to the following equation: ${ }^{46}$

$$
\tau=\frac{1}{k_{\mathrm{app}}}
$$

Assuming that the heterogeneous reactions of ozone with OA, LA and LOA are the only degradation processes occurring in the atmosphere. The values of $k_{\text {app }}$ for three reaction systems were calculated using eqn (2) at $10 \mathrm{ppm} \mathrm{O}_{3}$. For room 
temperature and dry conditions, the lifetime of OA, LA and LOA aerosols are determined to be $13.22,8.77 \mathrm{~min}$ and $8.17 \mathrm{~min}$, respectively. Taking into account the results from previous studies, when reacting with $\mathrm{O}_{3}$, Morris et al. ${ }^{57}$ also estimated a lifetime of a few minutes for pure oleic acid particles. And the methyl ester has a lifetime of $\sim 10 \mathrm{~min}$ when determined rate coefficient for the oxidation of D-methyl oleate at the air-water interface.$^{58}$ In contrast to these reports, the lifetimes of another organics in the atmosphere have been shown to be several orders of magnitude longer. For example, the lifetimes of pure maleic and fumaric acid aerosols are 19 and 30 hours, respectively, under room temperature and dry conditions; ${ }^{45}$ The lifetime of particle-phase vinclozolin at $100 \mathrm{ppbv}_{3}$ is $\sim 4.3$ hours. ${ }^{59}$ The short lifetime of the long-chain UFAs droplets is of atmospheric importance since these UFAs are more vulnerable to ozone, the removal of organic material from the atmospheric particles is extremely efficient as a result of this rapid atmospheric aging process. In addition, this rapid aging progress can substantially alter the surface tension and significantly change the optical and cloud nucleation properties of aqueous droplets in the atmosphere..$^{58}$ Kinetics studies indicate that although the lifetimes of pure UFAs in the atmosphere would be on the order of tens of minutes, the lifetime can increase to tens of hours when the reaction occurs in a liquid/solid matrix and the atmospheric particles might be transported over large distances. ${ }^{60}$ Consequently, the ozonation process plays an important role in the degradation of OA, LA and LOA under the natural environmental conditions.

Furthermore, heterogeneous reaction products of ozone with UFAs are likely to be sources of ester and hydroxyl groups to the atmosphere. The highly oxygenated products of the organic layer are of hydrophilicity and low volatility, which are the key factors to be as CCN with higher growth factors in humid environments. ${ }^{\mathbf{2 0 , 2 4 , 2 7}}$ The heterogeneous reaction kinetics show different dependences on RHs, which are related to the molecular structures of three organics and their oxidation products. The productions vary with the specific environmental conditions. If ozone oxidation occurs at the high $\mathrm{RH}$, the product yield may be high for LOA oxidized products but may be low for OA oxidized products. Moreover, with the increasing oxygen-to-carbon ratio, the oxidized particles seem to facilitate water uptake, leading to serious haze weather from the aging progresses.

\section{Conclusions}

In this study, a gas-flow system combined with micro-FTIR spectrometer was utilized to study reaction kinetics of ozone initiated heterogeneous oxidation of micron-sized OA, LA and LOA single droplets. All the overall kinetics is dominated by surface reactions which is the one of the achievement of present work. In order to establish a mechanistic framework, the reaction kinetics versus ozone concentration, particle sizes and ambient RH were observed. The effect of surface adsorption can play an important role in the reaction which is derived from the ozone concentration effects and particle sizes on reaction kinetics. Moreover, more double bonds lead to more efficient reaction due to the high reactivity of organic acids droplets with ozone from the $K_{\mathrm{m}}$ values of the Langmuir-Hinshelwood mechanism fittings. Increasing humidity is seen to accelerate the uptake process as the double bond numbers of the organic increase is the main highlight of this work. The kinetics of LA and LOA oxidization by ozone is found to be dependent on RH. And the $k_{\text {app }}$ and the $\gamma$ values increase more than 3 -fold as the $\mathrm{RH}$ increased from $\sim 0 \%$ to $83 \%$ for $\mathrm{LOA} / \mathrm{O}_{3}$ reaction. While, the $k_{\text {app }}$ and the $\gamma$ values of $\mathrm{LA} / \mathrm{O}_{3}$ reaction are increased only by $\sim 2$ fold which are weaker than $\mathrm{LOA} / \mathrm{O}_{3}$ system as the same $\mathrm{RH}$ range. For the $\mathrm{OA} / \mathrm{O}_{3}$ reaction, the $k_{\text {app }}$ and the $\gamma$ values exhibit a very weak RH dependence over the range of $0-85 \%$. Additional water uptake studies suggest that the hygroscopicities of the organics are strongly dependent upon the chemical structures of acids. The UFAs with more $\mathrm{C}=\mathrm{C}$ double bonds and their oxidized products present stronger hygroscopic property either by promoting the mobility of the original organic phase or by increasing the solubility and the residence time of ozone molecules at high $\mathrm{RH}$, which enhance the reaction rate in turn.

\section{Acknowledgements}

This work was financially supported by the National Natural Science Foundation of China (91544223, 41175119, 21473009 and 21373026).

\section{References}

1 M. Kanakidou, J. H. Seinfeld, S. N. Pandis, I. Barnes, F. J. Dentener, M. C. Facchini, R. Van Dingenen, B. Ervens, A. Nenes, C. J. Nielsen, E. Swietlicki, J. P. Putaud, Y. Balkanski, S. Fuzzi, J. Horth, G. K. Moortgat, R. Winterhalter, C. E. L. Myhre, K. Tsigaridis, E. Vignati, E. G. Stephanou and J. Wilson, Atmos. Chem. Phys., 2005, 5, 1053-1123.

2 X. Zhang, R. H. Schwantes, M. M. Coggon, C. L. Loza, K. A. Schilling, R. C. Flagan and J. H. Seinfeld, Atmos. Chem. Phys., 2014, 14, 1733-1753.

3 H. M. Hung and P. Ariya, J. Phys. Chem. A, 2007, 111, 620632.

4 Y. Rudich, N. M. Donahue and T. F. Mentel, Annu. Rev. Phys. Chem., 2007, 58, 321-352.

5 V. F. McNeill, R. L. N. Yatavelli, J. A. Thornton, C. B. Stipe and O. Landgrebe, Atmos. Chem. Phys., 2008, 8, 5465-5476.

6 B. T. Mmereki, D. J. Donaldson, J. B. Gilman, T. L. Eliason and V. Vaida, Atmos. Environ., 2004, 38, 6091-6103.

7 M. J. Molina, A. V. Ivanov, S. Trakhtenberg and L. T. Molina, Geophys. Res. Lett., 2004, 31, 359-393.

8 A. K. Bertram, A. V. Ivanov, M. Hunter, L. T. Molina and M. J. Molina, J. Phys. Chem. A, 2001, 105, 9415-9421.

9 L. R. Rinehart, E. M. Fujita, J. C. Chow, K. Magliano and B. Zielinska, Atmos. Environ., 2006, 40, 290-303.

10 K. Kawamura, Y. Ishimura and K. Yamazaki, Geochim. Cosmochim. Acta, 2003, 67, A208.

11 D. Fu, C. Leng, J. Kelley, G. Zeng, Y. Zhang and Y. Liu, Environ. Sci. Technol., 2013, 47, 10611-10618. 
12 H. M. Hung, Y. Katrib and S. T. Martin, J. Phys. Chem. A, 2005, 109, 4517-4530.

13 Y. Katrib, G. Biskos, P. R. Buseck, P. Davidovits, J. T. Jayne, M. Mochida, M. E. Wise, D. R. Worsnop and S. T. Martin, J. Phys. Chem. A, 2005, 109, 10910-10919.

14 T. Moise and Y. Rudich, J. Phys. Chem. A, 2002, 106, 64696476.

15 A. Asad, B. T. Mmereki and D. J. Donaldson, Atmos. Chem. Phys., 2004, 4, 2083-2089.

16 A. E. Kerenkan, F. Beland and T. O. Do, Catal. Sci. Technol., 2016, 6, 971-987.

17 R. C. Chapleski, Y. F. Zhang, D. Troya and J. R. Morris, Chem. Soc. Rev., 2016, 45, 3731-3746.

18 A. K. Y. Lee and C. K. Chan, J. Phys. Chem. A, 2007, 111, 62856295.

19 P. J. Ziemann, Faraday Discuss., 2005, 130, 469-490.

20 J. Zahardis and G. A. Petrucci, Atmos. Chem. Phys., 2007, 7, 1237-1274.

21 G. Zeng, S. Holladay, D. Langlois, Y. Zhang and Y. Liu, J. Phys. Chem. A, 2013, 117, 1963-1974.

22 C. B. Leng, J. Hiltner, H. Pham, J. Kelley, M. Mach, Y. H. Zhang and Y. Liu, Phys. Chem. Chem. Phys., 2014, 16, 4350-4360.

23 J. H. Slade, R. Thalman, J. Wang and D. A. Knopf, Atmos. Chem. Phys., 2015, 15, 10183-10201.

24 J. D. Hearn, A. J. Lovett and G. D. Smith, Phys. Chem. Chem. Phys., 2005, 7, 501-511.

25 T. Thornberry and J. P. D. Abbatt, Phys. Chem. Chem. Phys., 2004, 6, 84-93.

26 J. D. Hearn and G. D. Smith, J. Phys. Chem. A, 2004, 108, 10019-10029.

27 H. M. Hung and C. W. Tang, J. Phys. Chem. A, 2010, 114, 13104-13112.

28 H. Zhang, J. D. Surratt, Y. H. Lin, J. Bapat and R. M. Kamens, Atmos. Chem. Phys., 2011, 11, 6411-6424.

29 O. Vesna, M. Sax, M. Kalberer, A. Gaschen and M. Ammann, Atmos. Environ., 2009, 43, 3662-3669.

30 M. Mendez, N. Visez, S. Gosselin, V. Crenn, V. Riffault and D. Petitprez, J. Phys. Chem. A, 2014, 118, 9471-9481.

31 G. D. Smith, E. Woods, C. L. DeForest, T. Baer and R. E. Miller, J. Phys. Chem. A, 2002, 106, 8085-8095.

32 G. Zeng, Ph.D, Beijing Institute of Technology, 2015.

33 A. I. Flossmann and W. Wobrock, Atmos. Res., 2010, 97, 478497.

34 C. Price, Nature, 2000, 406, 290-293.

35 E. J. Palen, D. T. Allen, S. N. Pandis, S. E. Paulson, J. H. Seinfeld and R. C. Flagan, Atmos. Environ., 1992, 26, 1239-1251.

36 E. J. Palen, D. T. Allen, S. N. Pandis, S. Paulson, J. H. Seinfeld and R. C. Flagan, Atmos. Environ., 1993, 27, 1471-1477.
37 M. Segal-Rosenheimer and Y. Dubowski, J. Phys. Chem. C, 2007, 111, 11682-11691.

38 L. Petrick and Y. Dubowski, Indoor Air, 2009, 19, 381-391.

39 J. E. Roberts, G. Zeng, M. K. Maron, M. Mach, I. Dwebi and Y. Liu, J. Chem. Educ., 2016, 93, 733-737.

40 G. Zeng, S. Holladay, D. Langlois, Y. Zhang and Y. Liu, J. Phys. Chem. A, 2013, 117, 1963-1974.

41 E. Richaud, L. Audouin, B. Fayolle, J. Verdu, L. MatisovaRychla and J. Rychly, Chem. Phys. Lipids, 2012, 165, 753-759.

42 A. Tani, S. Fukui, S. Ikawa and K. Kitano, J. Phys. D: Appl. Phys., 2015, 48, 424010.

43 D. R. Worsnop, J. W. Morris, Q. Shi, P. Davidovits and C. E. Kolb, Geophys. Res. Lett., 2002, 29, 57-1-57-4.

44 X. He, C. B. Leng and Y. H. Zhang, Spectrosc. Spectral Anal., 2016, 36, 1576-1580.

45 J. J. Najera, C. J. Percival and A. B. Horn, Phys. Chem. Chem. Phys., 2009, 11, 9093-9103.

46 J. Ma, Y. Liu and H. He, Atmos. Environ., 2010, 44, 4446-4453.

47 V. F. McNeill, G. M. Wolfe and J. A. Thornton, J. Phys. Chem. A, 2007, 111, 1073-1083.

48 N. O. A. Kwamena, M. G. Staikova, D. J. Donaldson, I. J. George and J. P. D. Abbatt, J. Phys. Chem. A, 2007, 111, 11050-11058.

49 T. F. Kahan, N. O. A. Kwamena and D. J. Donaldson, Atmos. Environ., 2006, 40, 3448-3459.

50 Y. Liu, J. P. Cain, H. Wang and A. Laskin, J. Phys. Chem. A, 2007, 111, 10026-10043.

51 D. Langlois, S. Holladay and G. Zeng, Abstracts of Papers of the American Chemical Society, 2013, p. 245.

52 A. L. Goodman, P. Li, C. R. Usher and V. H. Grassian, J. Phys. Chem. A, 2001, 105, 6109-6120.

53 M. Farnesi Camellone, F. Negreiros Ribeiro, L. Szabova, Y. Tateyama and S. Fabris, J. Am. Chem. Soc., 138, 1156011567.

54 R. E. Peterson and B. J. Tyler, Appl. Surf. Sci., 2003, 203, 751756.

55 H. Tervahattu, K. Hartonen, V. M. Kerminen, K. Kupiainen, P. Aarnio, T. Koskentalo, A. F. Tuck and V. Vaida, J. Geophys. Res.: Atmos., 2002, 107, AAC 1-1-AAC 1-8.

56 L. M. Russell, S. F. Maria and S. C. B. Myneni, Geophys. Res. Lett., 2002, 29, 26-1-26-4.

57 J. W. Morris, P. Davidovits, J. T. Jayne, J. L. Jimenez, Q. Shi, C. E. Kolb, D. R. Worsnop, W. S. Barney and G. Cass, Geophys. Res. Lett., 2002, 29, 71-1-71-4.

58 C. Pfrang, F. Sebastiani, C. O. M. Lucas, M. D. King, I. D. Hoare, D. Chang and R. A. Campbell, Phys. Chem. Chem. Phys., 2014, 16, 13220-13228.

59 J. Gan, B. Yang, Y. Zhang, X. Shu, C. G. Liu and J. N. A. Shu, J. Phys. Chem. A, 2010, 114, 12231-12236.

60 P. J. Ziemann, Faraday Discuss., 2005, 130, 469. 